\title{
A ciência subordinada: coronavírus e a política científica no Brasil*
}

\author{
Subordinated science: the coronavirus \\ and scientific policy in Brazil
}

\section{Rogério Rosa Rodrigues ${ }^{i}$ \\ i Professor, Departamento de História/ Universidade do Estado de Santa Catarina. \\ Florianópolis - SC - Brasil orcid.org/0000-0002-5189-7095 rogerio.rodrigues@udesc.br}

Recebido em 13 ago. 2020. Aprovado em 15 nov. 2020.
RODRIGUES, Rogério Rosa. A ciência subordinada: coronavírus e a política científica no Brasil. História, Ciências, Saúde - Manguinhos, Rio de Janeiro, v.28, n.4, out.-dez. 2021, p.1281-1286.

Resumo

A política científica no Brasil tem negligenciado o papel das áreas humanas e sociais, sobretudo quanto a investimento em pesquisa. Com a pandemia de covid-19, as atenções se voltaram para minimizar o impacto da crise sanitária na vida social e econômica do país. No universo científico, isso se efetivou por meio de editais de fomento a pesquisa e bolsas de qualificação profissional que estabeleceram como prioritárias as áreas tecnológicas, restringindo as oportunidades de pesquisadores de ciências sociais, humanas e artísticas. Argumenta-se aqui que a política científica desenvolvida no Brasil está em descompasso com programas internacionais de desenvolvimento científico, demonstrando uma visão limitada do que é ciência, bem como de seu papel no desenvolvimento de uma nação.

Palavras-chave: coronavírus; ciência e tecnologia; política científica; trabalho docente.

\begin{abstract}
Scientific policy in Brazil has neglected the human and social sciences, especially in terms of investing in research. With the arrival of covid-19, efforts have focused on minimizing the impact of this health crisis on the country's social and economic life. In the scientific arena, this involved research financing and professional qualification grants that prioritized technological areas while restricting opportunities for researchers from the social, human, and artistic sciences. Here we maintain that Brazil's scientific policy is out of step with international scientific development programs, and has a limited view of what science is, as well as its role in the nation's development.
\end{abstract}

Keywords: coronavirus; science and technology; scientific policy; teaching work. 
$\mathrm{N}_{\mathrm{n}}^{\circ}$ dia 23 de abril de 2020 foram anunciados novos critérios de distribuição das 25 mil ${ }^{1}$ bolsas de iniciação científica. ${ }^{2} \mathrm{Na}$ chamada divulgada pelo Conselho Nacional de Desenvolvimento Científico e Tecnológico (CNPq), somente projetos com alguma aderência a uma das cinco áreas consideradas prioritárias pelo Ministério de Ciência, Tecnologia, Inovações e Comunicações (MCTIC) seriam contemplados com as bolsas do Programa Institucional de Iniciação Científica/2020/2021. ${ }^{3}$ Segundo a presidente da Comissão de Pesquisa da Faculdade de Direito da Universidade de São Paulo, Nina Ranieri (8 maio 2020), desde sua criação, em 1988, "é a primeira vez na história do Pibic que limitações temáticas são impostas à concessão de bolsas, o que contraria os objetivos do programa, centrados no despertar de vocações científicas e no incentivo a novos talentos entre estudantes de graduação". Após o anúncio oficial, inúmeras instituições de pesquisa e ensino, assim como entidades científicas do país, posicionaram-se sobre tal decisão, incluindo os próprios titulares dos comitês de assessoramento das áreas de ciências humanas, sociais e sociais aplicadas junto ao CNPq. ${ }^{4}$

De acordo com depoimento divulgado no vídeo institucional do MCTIC na noite de 12 de maio de 2020, essa restrição tem como proposta priorizar os projetos diretamente relacionados a atividades que chegarão de forma mais direta ao cidadão por meio de produtos com potencial de inovação científica e tecnológica. ${ }^{5}$ Outra preocupação aparentemente subsidiária dessa decisão diz respeito a investimentos em projetos que possam contribuir no combate e na redução da disseminação da covid-19, bem como suas consequências. No entanto, reduzir o combate aos problemas advindos da pandemia a projetos de cunho tecnológico - que hierarquiza algumas áreas e exclui diversas ciências - revela uma visão equivocada do que é ciência e de qual o seu papel em momentos de crises como esta que vivemos.

No momento em que tanto se alerta sobre a importância de ouvir os cientistas, é no mínimo prudente ressaltar que a ciência cobre um campo vastíssimo de áreas de conhecimento. E isso inclui projetos de pesquisa básica, humanidades e ciências sociais. Mas por que essas áreas do conhecimento mereceriam ser consideradas áreas prioritárias?

Um dos aspectos mais traumáticos dessa pandemia é a impossibilidade de realização de rituais de sepultamento. Além do trauma imediato dos familiares, impossibilitados de ver o rosto do ente amado pela última vez, teremos uma geração que não operará o luto necessário para celebrar sua própria vida enquanto cultua a memória do ente que partiu. Isso se agrava diante da proibição de rituais fúnebres e, em casos mais extremos, de um túmulo individualizado que permita saber onde repousa o corpo do morto. Qual tecnologia, entre as prioritárias listadas no comunicado oficial do CNPq, ajudará e encontrar solução para problemas dessa natureza?

Quando os profissionais da saúde e as lideranças políticas necessitam escolher quem deve viver e quem pode morrer, não entramos em um dilema ético e moral? Acaso serão as ciências prioritárias listadas pelo MCTIC as únicas a minimizar os efeitos dessa decisão? No momento em que verificamos os índices de alastramento da covid-19 nas periferias, nas terras quilombolas e indígenas, a chegada da fome e do desemprego nas comunidades, não se trata de um problema que exige esforços de todas as áreas da ciência?

As escolas estão funcionando de forma híbrida. Isso significa dupla jornada de trabalho para grande parte dos professores, que precisam organizar atividades remotas e também se 
deslocar até a escola para ministrar suas aulas de forma presencial. São dois planejamentos, duas metodologias, duas formas de exposição pública. Problemas de depressão e síndrome do pânico têm sido comum entre os docentes, que tiveram que se reinventar como profissionais e ainda administrar as angústias criadas pela crescente demanda de pais e alunos, além de, não raras vezes, lidar com os dilemas familiares criados pela presença de filhos e familiares em situação de vulnerabilidade social.

Plataformas que permitem aplicar ações educativas para alunos e alunas confinados em seus lares estão com um índice de acesso nunca visto antes na história da vida digital, e uma demanda política por instalação de ensino a distância em todos os níveis de ensino tem sido frequente por parte de conglomerados educacionais. ${ }^{6}$ Isso é unicamente um problema das áreas tecnológicas? O aspecto didático-pedagógico não merece destaque nos investimentos públicos de enfrentamento aos problemas gerados por esse infortúnio natural que puxou o freio da história? A negligência com essas questões tem efeitos imediatos, mas que ficarão mais graves no futuro. Não valeria investir agora nas pesquisas sobre educação, didática, filosofia, letras, artes, geografia e tantas outras áreas do conhecimento para prevenir problemas de ordem pedagógica e psicológica que estão afetando professores, alunos e familiares no decorrer dessa pandemia e que seguramente se prolongarão quando tudo isso passar?

O combate ao coronavírus tem gerado uma infinidade de documentos que implicarão filtragem, seleção, organização, sistematização e, sobretudo, interpretação. Arquivistas, bibliotecários, historiadores e tantos outros profissionais das ciências humanas não merecem prioridade nesta batalha? Para quem tem dúvidas, vale a pena ler a matéria da jornalista Juliana Sayuri (12 maio 2020) sobre iniciativas de historiadores no Brasil e no mundo relacionadas à pandemia do coronavírus desde a sua emergência global. Entre as ações, constam incentivos à produção de diários pessoais, conversas com especialistas em ambientes virtuais e preocupação em desmontar narrativas negacionistas e conspirativas sobre a pandemia. Iniciativas promovidas, em grande medida, por profissionais da área das ciências humanas.

Malgrado a ausência de uma política emergencial de apoio, muitos artistas têm trabalhado para que o presente não se alimente apenas das crônicas diárias que os noticiários repetem como um mantra a ponto de deixar imobilizados uns, e indiferentes outros. Neste momento em que o isolamento social nos coloca diante das dores e das delícias do nosso cotidiano (mais dores do que delícias, vale registrar), a arte nos propõe sair do modo remoto, nos confrontar com o diferente e as diferenças. Alternativas de exibições de gravações de montagens teatrais, músicas escapando das janelas dos edifícios, declamação de poesia e bate-papo com artistas têm sido algumas das muitas alternativas da classe artística em meio ao confinamento social. Acaso elas não merecem amparo entre os investimentos prioritários no combate aos problemas causados por esse vírus?

Em matéria publicada no blog Café História, a jornalista Laura Chaparro (20 abr. 2020) aborda a importância de os governantes utilizarem todas as áreas científicas para combater crises epidêmicas como a que estamos atravessando. Ela reproduz a fala do diretor executivo da Academia Britânica, Hetan Shah, que afirma: "se quisermos superar esses vírus, precisaremos da experiência e do conhecimento de uma ampla variedade de disciplinas, 
desde ciências sociais e humanas até medicina, biologia e engenharia" (Chaparro, 20 abr. 2020). O trabalho da antropóloga Melissa Leach na luta contra o ebola em Serra Leoa foi apresentado como exemplo. Essa pesquisadora conseguiu convencer a comunidade a substituir os rituais tradicionais de enterro por rituais não presenciais. ${ }^{7}$

Em solo brasileiro, vale mencionar a iniciativa da Associação Brasileira de Estudos Cemiteriais (Abec). ${ }^{8}$ São historiadores, museológicos e antropólogos que, a partir de um documento montado por equipe espanhola, organizaram um guia para pessoas que perdem um ente querido em tempos de coronavírus. ${ }^{9}$ Em suas 53 páginas, o documento apresenta propostas de rituais de despedidas individuais e sociais a distância, recomenda os cuidados com os familiares das vítimas e instrui agentes funerários, parentes e amigos. Essa mesma associação faz parte de uma rede coletiva na internet chamada Memorial das Vítimas do Coronavírus no Brasil. Entre as medidas de auxílio aos familiares das vítimas da covid-19 efetuadas por essa rede, constam: (a) orientações básicas e gerais para as famílias de vítimas fatais da doença; (b) orientações para velórios, sepultamentos e rituais de despedida; (c) acolhimento, assistência e amparo psicossocial imediatos e continuados após o trauma; (d) canais para garantir o direito à memória, ao luto, ao velório e às devidas homenagens aos mortos; (e) rede de jornalistas e cientistas sociais para levantamento de informações dos casos, circunstâncias das mortes, eventuais denúncias e registro das histórias de vida; (f) estudo para viabilizar um "Fundo de solidariedade emergencial para apoio imediato a familiares de vítimas da covid-19". ${ }^{10}$ Mais de sessenta associações se aliam a essa iniciativa, incluindo associações artísticas, científicas e de organização civil.

Além dessas questões práticas, que atendem aos problemas que se apresentam no momento, é preciso destacar a importância do próprio exercício de refletir e teorizar sobre a pandemia. Como bem destacou Ghassan Hage ao dissertar acerca do papel dos intelectuais práticos e dos chamados intelectuais críticos em momentos que exigem tomadas de decisão imediatas,

se o vírus parece assumir uma força associal, e o esforço em contê-lo, seja por meio da prevenção ou da medicação, continua sendo um esforço social. Por isso, ele é marcado por todos os preconceitos e relações de poder que definem qualquer ação humana: racismo, colonialismo, preconceito de classe, sexismo, preconceitos heteronormativos. Tudo isso participa da conformação dos modos como uma sociedade lida com um vírus (Hage, s.d.).

Hage debate o sentido de utilidade no campo científico. Útil, para esse intelectual, remete a algo participativo, "algo que expande a vida das pessoas". Ele cita a paisagem, o som dos pássaros, a poesia. Poderíamos acrescentar as lives diárias da cantora Teresa Cristina, os depoimentos emocionantes de professores e professoras sobre os desafios de ensinar de forma remota, organizados pelo Laboratório de Imagem e Som da Universidade do Estado de Santa Catarina, as visitas virtuais disponibilizadas pelos museus no Brasil e no exterior e tantas outras iniciativas que expandem nossa imaginação, nossa compreensão do mundo e de nós mesmos. Ações utilitárias que instauram um instante em que, apesar do vírus, somos capazes de respirar sem medo de morrer. O fato de o edital do CNPq não apreender essa forma ampliada de utilidade científica diz mais sobre quem governa do que sobre a pandemia, revela antes a politização da ciência, não sua democratização. 
Como bem destacaram Mizoguchi e Passos (s.d.), vivemos uma espécie de pandemia política que tem desmontado direitos adquiridos desde a Constituição de 1988, apostando antes na anormalidade do que na estabilidade. Em suas palavras, "o uso político da crise da pandemia é no sentido do agravamento da insegurança", e não tanto de sua resolução. A ciência, nesse contexto pandêmico, vira moeda de troca, peça utilitária que confunde combate prioritário com política científica de impacto social.

Por trás da limitação das bolsas de iniciação científica às ciências ditas prioritárias subjaz uma ação que busca confiscar as potencialidades da própria ciência e instrumentalizá-las politicamente. Uma espécie de desejo totalitário de gerir o estado de exceção emergente com a pandemia. Algo que precisamos refutar, em qualquer campo científico que estejamos.

Se aceitarmos a naturalização da política de subordinação de algumas ciências em relação a outras, teremos como consequência o próprio definhamento da ciência e, com ela, de todas as ações advindas das diversas áreas do conhecimento que chegam até a sociedade. Perde a ciência, mas também o mundo, sobretudo o social, político e cultural, sem o qual deixamos de ser humanos e nos tornamos máquinas.

\section{NOTA}

* O presente texto é uma versão mais completa, atualizada e submetida a revisão por pares de uma postagem veiculada no blog de História, Ciências, Saúde - Manguinhos.

${ }^{1}$ O ministro da Ciência, Tecnologia, Inovações e Comunicações, Marcos Cesar Pontes, divulgou em vídeo no Youtube que a esse número foram acrescidas mil bolsas, portanto, 26 mil bolsas Pibic no total. Material publicado na noite de 12 de maio de 2020. Disponível em: https://www.youtube.com/ watch? $=$ FAudXJ4td98.

${ }^{2}$ A chamada do Conselho Nacional do Desenvolvimento Científico e Tecnológico (CNPq) está disponível em: http://www.cnpq.br/web/guest/noticiasviews/-/journal_content/56_INSTANCE_a6MO/10157/8920772.

${ }^{3}$ A portaria está disponível em: https://www.mctic.gov.br/mctic/opencms/legislacao/portarias/Portaria_ MCTIC_n_1122_de_19032020.html.

${ }^{4}$ A carta dirigida ao ministro Sérgio Pontes e ao presidente do CNPq está disponível em: https://www. apufsc.org.br/2020/05/07/pesquisadores-se-manifestam-pela-manutencao-de-bolsas-pibic.

${ }^{5}$ Vídeo disponível em: https://www.youtube.com/watch?v=FAudXJ4td98.

${ }^{6}$ Para uma avaliação do impacto da pandemia na atividade docente, acessar o dossiê "Trabalho docente em tempos de pandemia", publicado pela revista Retratos da Escola (v.14, n.30), periódico vinculado ao Conselho Nacional de Trabalhadores da Educação (CNTE). Disponível em: http://retratosdaescola.emnuvens.com. $\mathrm{br} / \mathrm{rde} /$ issue/view/40.

${ }^{7}$ As ações dessa pesquisa podem ser acessadas em plataforma disponível para registrar e divulgar os resultados para a comunidade. Disponível em: http://www.ebola-anthropology.net.

${ }^{8}$ A Abec foi criada em 2004 e tem desenvolvido trabalho importante na área de pesquisa, conservação e patrimonialização de espaços cemiteriais no Brasil. No site da associação é possível encontrar os registros das ações que ela tem desenvolvido. Disponível em: https://www.estudoscemiteriais.com.br/memorialvitimas-coronavirus.

${ }^{9}$ A íntegra do documento está disponível em: https://78cc12e9-d1b5-405a-80b9-d742dc00115d.filesusr. com/ugd/a77533_902c8c6ce84e4db587e341e0df63de7c.pdf.

${ }^{10}$ A página da rede que montou esse material é atualizada diariamente. Ela reúne mais de sessenta organizações da sociedade civil, de caráter científico, artístico, jurídico ou social. Disponível em: https:// www.facebook.com/memorialcoronabrasil/posts/133783131601224:0?tn__=K-R. 


\section{REFERÊNCIAS}

CHAPARRO, Laura. A medicina não é suficiente: por que precisamos das ciências sociais para acabar com essa pandemia. Trad. Bruno Leal. Café História: História feita com clique, 20 abr. 2020. Disponível em: https://www.cafehistoria. com.br/ciencias-sociais-novo-coronaviruspandemia. Acesso em 12 ago. 2020.

HAGE, Ghassan. O fantasma do acadêmico inútil: pensamento crítico em tempos de coronavírus. $N$-1 edições, (99), s.d. Disponível em: https://www.n-1edicoes.org/textos/12. Acesso em: 5 abr. 2020.

MIZOGUCHI, Danichi Hausen; PASSOS, Eduardo. Epidemiologia política. $\mathrm{N}$-1 edições, (15), s.d. Disponível em: https://www.n1edicoes.org/textos/48. Acesso em: 12 ago. 2020.
RANIERI, Nina. Limitações temáticas das bolsas de iniciação científica ferem a Constiuição e as leis. O Estado de São Paulo, 8 maio 2020. Disponível em: https://politica.estadao.com.br/ blogs/fausto-macedo/limitacoes-tematicas-dasbolsas-cientificas-ferem-a-constituicao-e-as-leis. Acesso em: 12 maio 2020.

SAYURI, Juliana. Covid-19: como historiadores vão contar o que foi a pandemia. TAB, 12 maio 2020. Disponível em: https://tab.uol.com.br/ noticias/redacao/2020/05/12/covid-19-comohistoriadores-vao-contar-o-que-foi-a-pandemia. htm. Acesso em: 12 maio 2020.

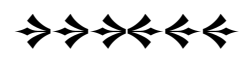

